\title{
BASES MORFOFISIOLÓGICAS PARA MAIOR TOLERÂNCIA DOS HÍBRIDOS MODERNOS DE MILHO A ALTAS DENSIDADES DE PLANTAS ${ }^{(1)}$
}

\author{
LUÍS SANGOI(2,5); MILTON LUIZ DE ALMEIDA ${ }^{(2,5)}$; \\ PAULO REGIS FERREIRA DA SILVA ${ }^{(3,5)}$; GILBER ARGENTA ${ }^{(4)}$
}

\begin{abstract}
RESUMO
O lançamento de híbridos de milho tolerantes ao aumento da densidade de plantas contribuiu para o incremento do potencial produtivo da cultura na segunda metade do século XX. Objetiva-se com esta revisão de literatura discutir características morfológicas, fisiológicas, fenológicas e alométricas que contribuíram para maior adaptação do milho a elevadas densidades de plantas. Os processos de seleção utilizados pelos melhoristas minimizaram a natureza protândrica da planta, reduzindo o tamanho do pendão. Isso propiciou desenvolvimento alométrico mais equilibrado entre as inflorescências masculina e feminina, limitou a esterilidade feminina e favoreceu a sincronia entre antese e espigamento. O ideotipo de planta compacto dos híbridos modernos, caracterizado pela presença de plantas baixas, com menor número de folhas e folhas eretas, melhorou a qualidade da luz no interior do dossel, contribuindo para reduzir a dominância apical do pendão sobre as espigas. A menor produção de fitomassa reduziu a competição intra-específica e aumentou a eficiência de uso dos fatores ambientais, disponibilizando mais carboidratos para atender às diferentes demandas da planta na fase reprodutiva. O maior equilíbrio nas relações entre fonte e dreno contribuiu para retardar a senescência foliar, resultando em maior absorção de nutrientes e maior eficiência de uso do nitrogênio. O desenvolvimento de híbridos com menor estatura e espigas mais próximas do solo reduziu a quantidade de plantas acamadas e quebradas. A compreensão das bases morfofisiológicas responsáveis pela maior tolerância do milho à competição intra-específica auxiliará melhoristas e fisiologistas a maximizar a eficiência do arranjo de plantas para alcançar altos rendimentos.
\end{abstract}

Palavras-chave: Zea mays, estresse, população, rendimento de grãos.

\section{ABSTRACT \\ MORPHO-PHYSIOLOGICAL BASES FOR GREATER TOLERANCE OF MODERN MAIZE HYBRIDS TO HIGH PLANT DENSITIES}

The release of maize hybrids tolerant to high plant densities has contributed to enhance the potential for grain yield in this crop in the second half of last century. This review aims to discuss morphological and physiological traits that favoured maize adaptation to dense stands. The selection by breeders mitigated maize protandrous nature, reducing tassel size and promoting a balanced development of male and female inflorescence. Barrenness was limited and the synchrony of anthesis and silking favoured. The modern hybrid compact ideotype, characterized by small plants, low leaf number and upright leaves, improved light quality inside the canopy, decreasing apical dominance of the tassel over the ears. The lower dry matter produced per plant decreased plant competition by neighbours, increased radiation use efficiency, supporting higher carbohydrate availability to match maize different sinks during grain filling. The more equilibrated source: sink ratio was instrumental to delay leaf senescence, keeping nutrient uptake at the end of the crop cycle and improving nitrogen efficiency usage. The development of hybrids with short plant stature and low ear insertion reduced lodging. The understanding of physiological basis underlying maize endurance to high densities allows breeders and plant physiologists to optimize plant arrangement in order to accomplish higher grain yields.

Key words: Zea mays, stress, population, grain yield.

$\left(^{1}\right)$ Recebido para publicação em 5 de dezembro de 2001 e aceito em 11 de junho de 2002.

(') Departamento de Fitotecnia, Universidade do Estado de Santa Catarina (UDESC), Av. Luiz de Camões, 2090, Caixa Postal 281, 88520-000 Lages (SC). E-mail: a2ls@cav.udesc.br

(3) Departamento de Plantas de Lavoura, Universidade Federal do Rio Grande do Sul (UFRGS), Av. Bento Gonçalves, 7712, Caixa Postal 776, 91540-000 Porto Alegre (RS). E-mail: paulo.silva@vortex.ufrgs.br

$\left(^{4}\right)$ Fundação Estadual de Pesquisa Agropecuária (FEPAGRO), Rua Gonçalves Dias, 570, 90130-060 Porto Alegre (RS). E-mail: argenta@cpovo.net

$\left({ }^{5}\right)$ Com bolsa de produtividade científica do CNPq. 


\section{INTRODUÇÃO}

O milho é a cultura que apresentou maior incremento no seu potencial produtivo na segunda metade do século XX, expressando ganhos em produtividade de $1,0 \%$ a $1,5 \%$ por ano, nas diferentes regiões do mundo (Slaffer e Otegui, 2000). O aumento do rendimento potencial do milho tem sido atribuído ao lançamento de cultivares com maior vigor híbrido e as modificações nas práticas culturais, tais como melhor controle de pragas, doenças e plantas daninhas, maior utilização de fertilizantes nitrogenados e aumento na densidade de plantas (TollenaAr et al., 1994).

A densidade de plantas é uma das práticas culturais que mais interfere no rendimento de grãos de milho, em virtude da pequena capacidade de emissão de afilhos férteis da cultura, da sua organização floral monóica e do curto período de florescimento (SANGOI, 2001). A utilização de densidades elevadas estimula a dominância apical (SANGOI, 1996). Com isso, a planta investe a maior parte dos recursos disponíveis na produção e dispersão de pólen às custas da redução nas taxas de crescimento e desenvolvimento da espiga e dos estigmas, levando à esterilidade feminina e à assincronia entre antese e espigamento (SANGOI e SALVADOR, 1998a).

Obtém-se o incremento na tolerância a altas densidades utilizando como critério principal de seleção o rendimento de grãos dos futuros híbridos de milho, avaliados em populações superiores às normalmente recomendadas (BOLAGÑOS e EDMEADES, 1996). Essa estratégia tem-se mostrado efetiva para aumentar a sincronia entre o florescimento masculino e feminino e, conseqüentemente, o rendimento de grãos. Contudo, sabe-se pouco sobre a contribuição de características morfológicas, fisiológicas, fenológicas e alométricas para a maior tolerância dos híbridos modernos de milho a densidades elevadas (KiRINI e Otegui, 2000).

Esta revisão de literatura tem como objetivo principal elucidar as principais características fenotípicas responsáveis pelo melhor desempenho dos híbridos cultivados atualmente em ambientes de elevada competição intra-específica.

\section{DESENVOLVIMENTO}

\subsection{Ontogenia e alometria das inflorescências}

A definição do rendimento de grãos de milho é um processo seqüencial, no qual se determina, primeiramente, o número de espigas por planta; a seguir, o número de grãos por espiga e a massa de grãos. Variações no suprimento de carbono e nitrogênio induzidas por diferentes populações podem afetar o rendimento de grãos e seus componentes seqüencialmente (JACOBS e PEARSON, 1991).

A esterilidade feminina é um dos principais fatores limitantes à otimização da conversão da energia solar à produção de grãos quando o milho é semeado em altas densidades (SANGOI, 1996). A compreensão da completa ontogenia envolvida desde a diferenciação da espiga até a exteriorização dos estigmas é fundamental para explicar os efeitos da alta densidade na supressão da produção de espigas e para elucidar mecanismos que permitem aos híbridos modernos de milho apresentar menores taxas de esterilidade feminina sob alta população.

A primeira alteração fisiológica que afeta o número de espigas férteis produzidas por planta é o intervalo de tempo decorrido entre a diferenciação das inflorescências masculina e feminina. O milho é uma planta monóica e protândrica, na qual a inflorescência masculina, oriunda do ponto de crescimento da planta, é diferenciada antes da inflorescência feminina, produzida no ápice de ramificações laterais (CHENG e PAREDY, 1994). O meristema é transformado num primórdio de inflorescência masculina quando a planta apresenta de cinco a seis folhas expandidas (RITCHIE e HANWAY, 1993). A gema lateral que originará a espiga superior transforma-se num primórdio floral alguns dias após a diferenciação do pendão, quando o milho possui de seis a sete folhas expandidas. Altas densidades de semeadura reduzem, de forma mais acentuada, a taxa e o crescimento das gemas laterais que do ponto de crescimento da planta. Isso aumenta a defasagem temporal entre a diferenciação do pendão e da espiga superior (SANGOI e SALVADOR, 1996). O aumento desse intervalo altera as taxas de transporte de fitormônios e carboidratos dentro da planta. Assim, espigas iniciadas tardiamente recebem menores quantidades dessas substâncias, tendo menos possibilidades de se tornarem funcionais e produzirem grãos, em decorrência da menor capacidade competitiva por fotoassimilados da espiga com as demais estruturas da planta (SANGOI, 2001).

Além da competição por fotoassimilados entre os diferentes órgãos, mecanismos hormonais estão envolvidos no efeito exercido pela densidade de plantas sobre o desenvolvimento das espigas (SANGOI e SAlvador, 1998b). Imediatamente após a transformação do ponto de crescimento num primórdio floral masculino, este começa a produzir grandes quantidades de auxinas que desencadeiam intensa atividade de divisão e elongação celular, resultando em incremento marcante na estatura e na produção de massa seca da planta (RITCHIE e HANWAY, 1993). Em alta densidade, as plantas estão mais próximas entre si nas linhas de cultivo, fazendo com que menor quantidade de radiação solar atinja o ponto de crescimento da planta (GARDNER et al., 1985). Radiação solar em alta intensidade ou quantidade pode oxidar e inativar parte das auxinas produzidas 
pelo meristema apical (SAlisburry e Ross, 1992). Portanto, em altas densidades de plantas há menor inativação e maior atividade das auxinas dentro da planta. Como a concentração de auxinas necessária para o desenvolvimento do pendão é muito superior à requerida para a formação das espigas (SANGOI et al., 1998), a utilização de altas densidades estimula uma dominância apical de natureza hormonal do pendão sobre as espigas, suprimindo o desenvolvimento das gemas axilares e levando à esterilidade feminina (SANGOI e SALVADOR, 1997).

A pressão de seleção aplicada pelos melhoristas para adaptar os híbridos modernos de milho ao adensamento minimizou paralelamente a natureza protândrica da planta de milho, reduzindo o intervalo ontogênico entre a diferenciação das inflorescências masculina e feminina (SANGOI, 2001). Isso propiciou o desenvolvimento de híbridos com relação alométrica mais favorável entre pendão e espigas (MUNDSTOCK, 1999). Dessa forma, os híbridos modernos produzem pendões menores (Duvick e CASSMANN, 1999) que requerem menor quantidade de nutrientes e fotoassimilados para suportar o seu desenvolvimento (SANGOI e SALVADOR, 1998b). Além disso, eles produzem menores quantidades de auxinas, diminuindo o seu efeito inibitório sobre o desenvolvimento das espigas (SANGOI e SALVADOR, 1996). Assim, o menor poder de demanda e a menor dominância apical do pendão sobre as espigas são causas importantes para o maior número de espigas por planta e melhor sincronia floral dos híbridos

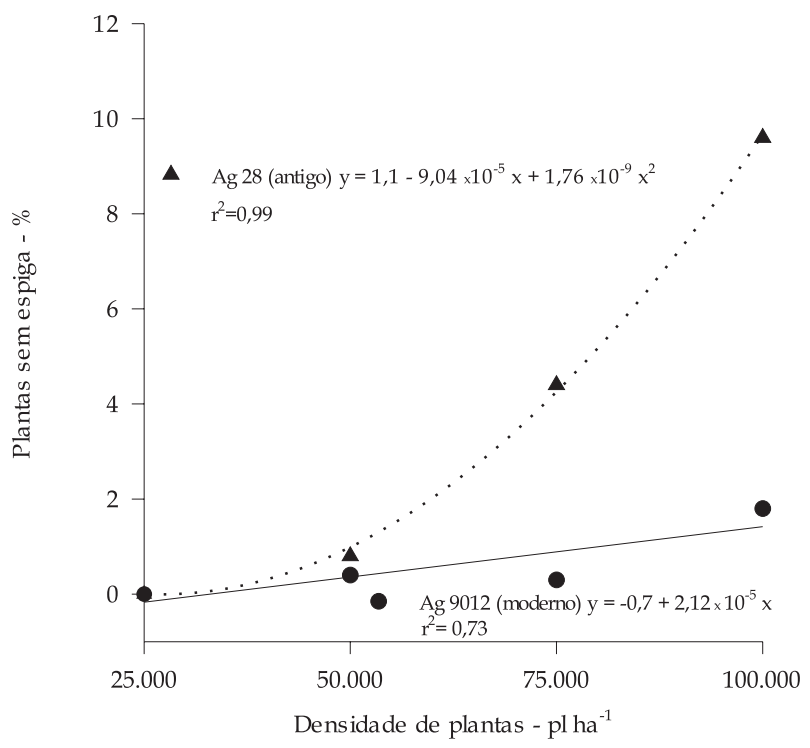

Figura 1. Efeitos da densidade de plantas sobre a esterilidade feminina de um híbrido de milho cultivado na década de 70 (Agroceres 28) e um híbrido de milho cultivado na década de 90 (Agroceres 9012). Lages, SC, 1997/98 (SANGOI et al., 1998). modernos de milho em densidades elevadas. As figuras 1 e 2 apresentam dados de SANGOI et al. (1998), os quais corroboram essa idéia, caracterizando os efeitos da densidade de plantas sobre a esterilidade feminina e a alocação de matéria seca ao pendão de híbridos lançados para cultivo em diferentes épocas respectivamente.

\subsection{Arquitetura de planta, qualidade da luz e sincronia floral}

Em adição aos aspectos hormonais envolvidos na dominância apical do pendão sobre as espigas, é importante considerar o papel regulatório dos fitocromos como sensores do grau de fechamento da comunidade e da intensidade da competição intraespecífica no dossel. Pesquisas realizadas com diversas espécies têm demonstrado que a quantidade de radiação nas faixas do vermelho extremo (Ve) e vermelho $(\mathrm{V})$ pode regular, por meio dos fitocromos, a distribuição dos fotoassimilados e o padrão de crescimento externado pelas plantas (ALMEIDA, 1998). Quando a densidade é alta, a distância entre plantas diminui, o que eleva a quantidade de radiação na faixa do vermelho extremo refletida pelas plantas da comunidade, aumentando a relação $\mathrm{Ve} / \mathrm{V}$ (Kasperbauer e Karlen, 1994; Almeida et al., 2000a).

$\mathrm{O}$ aumento da relação $\mathrm{Ve} / \mathrm{V}$ decorrente do incremento na densidade de plantas suprime o desenvolvimento de perfilhos em trigo, estimulando a dominância apical (AlmeidA et al., 2002). Como as espigas de milho são formadas na extremidade de

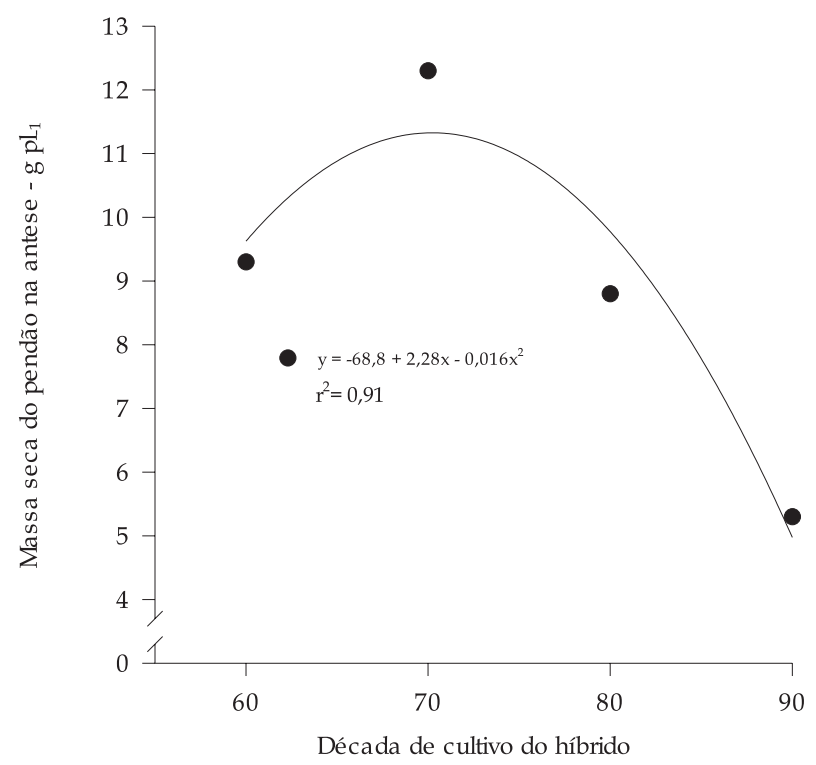

Figura 2. Massa seca acumulada no pendão durante a antese de híbridos de milho cultivados nas décadas de 60 (Agroceres 12), 70 (Agroceres 28), 80 (Agroceres 303) e 90 (Agroceres 9012), Lages, SC, 1997/98 (SANGOI et al., 1998). 
ramificações laterais, morfologicamente análogas aos perfilhos do trigo, infere-se que as alterações na qualidade da luz promovidas pelo aumento na densidade também contribuem para a maior esterilidade feminina do milho em altas densidades (SANGOI, 2001). Dessa forma, o intenso adensamento aumenta a relação $\mathrm{Ve} / \mathrm{V}$, desencadeando eventos fisiológicos que levam a planta a priorizar a alocação de fotoassimilados para o caule principal, resultando na supressão do desenvolvimento de ramificações laterais.

A maior parte dos híbridos cultivados atualmente no Sul do Brasil é menos exigente em unidades de calor para florescer e possui um fenótipo de planta mais compacto que o externado pelos híbridos utilizados em décadas passadas (SANGOI et al., 2001a). A arquitetura de planta dos híbridos modernos de milho interfere na qualidade da luz que penetra no dossel, contribuindo para sua maior tolerância a densidades elevadas. O desenvolvimento de genótipos com menor número de folhas, folhas mais eretas e menor área foliar minimiza a competição entre plantas, reduzindo a quantidade de vermelho extremo refletida pela comunidade (ALMEIDA et al., $2000 b)$. Com isso, pode-se obter uma relação $\mathrm{Ve} / \mathrm{V}$ mais baixa em altas densidades, quando comparada com os híbridos antigos, dotados de folhas mais numerosas, maiores e decumbentes. Assim, a melhoria na qualidade da luz, obtida com o ideotipo característico dos híbridos modernos de milho, pode propiciar condições endógenas para um desenvolvimento alométrico mais equilibrado entre as inflorescências da planta, minimizando a esterilidade feminina e propiciando melhores condições para o desenvolvimento de maior número de espiguetas funcionais na espiga (SANGOI, 2001). No quadro 1, observam-se características relativas à morfologia foliar de híbridos de milho de diferentes épocas, reportadas por SANGOI et al. (2001a).
2.3. Número de grãos por espiga, arquitetura de planta e eficiência de uso da radiação solar

O rendimento de grãos do milho está diretamente associado às variações no número de grãos por espiga, o qual dependerá das taxas de crescimento externadas pela cultura durante o florescimento (OtEGUI et al., 1995; CANTARERO et al., 1999). O atraso na transformação das ramificações laterais em primórdios de espiga, observado em altas densidades de plantas, pode afetar o número final de grãos por espiga pelas alterações morfofisiológicas impostas à inflorescência feminina antes do florescimento, durante a fertilização e no início do enchimento de grãos (ANDRADE et al., 2000).

Altas densidades reduzem o suprimento de nitrogênio (LEMCOFF e LoOMIS, 1994), fotoassimilados (Jacobs e PeArson, 1991) e água (Westgate, 1994) às espigas. Tais restrições atrasam os eventos ontogênicos vitais ao desenvolvimento da espiga, reduzindo o número de espiguetas femininas que apresentam flores férteis na fase de florescimento (KIRINY e OTEGUI, 2000) e retardando a exteriorização dos estigmas (SANGOI e SALVADOR, 1998a). O aumento na defasagem entre antese e espigamento, ocorrido quando se incrementa a densidade de plantas tem sido freqüentemente reportado na literatura (Регхото et al., 1997; SiLva et al., 1992; AlmEIDA et al., 2000b). Como o período de liberação de pólen da planta é curto e definido, a assincronia entre antese e espigamento, promovida por densidades elevadas, contribui substancialmente para reduzir o número de espiguetas fertilizadas, sendo decisiva para a redução no rendimento potencial da cultura (SANGOI e SALVADOR, 1998c).

O número de grãos por espiga em densidades elevadas também pode ser reduzido pelo aborto de

Quadro 1. Características morfológicas dos híbridos de milho Agroceres 12 e Agroceres 303, lançados nas décadas de 60 e 80 respectivamente, e Cargill 929, cultivado atualmente. Lages (SC), 2000/2001 ${ }^{(1)}$

\begin{tabular}{llll}
\hline \multicolumn{1}{c}{ Características } & Agroceres 12 & Agroceres 303 & Cargill 929 \\
\hline Massa seca do pendão & $13,5 \mathrm{a}$ & $12,4 \mathrm{~b}$ & $10,4 \mathrm{c}$ \\
Total de folhas & $23,2 \mathrm{a}$ & $22,2 \mathrm{a}$ & $18,4 \mathrm{~b}$ \\
Comprimento da folha & $81 \mathrm{a}$ & $86 \mathrm{a}$ & $73 \mathrm{~b}$ \\
Ponto de inflexão da folha & $27 \mathrm{~b}$ & $27 \mathrm{~b}$ & $40 \mathrm{a}$ \\
Área foliar & $8.114 \mathrm{a}$ & $8.662 \mathrm{a}$ & $7.316 \mathrm{~b}$ \\
Estatura da planta & $302 \mathrm{a}$ & $288 \mathrm{~b}$ & $251 \mathrm{c}$ \\
\hline
\end{tabular}

(1) Valores médios de quatro densidades de plantas: 25.000, 50.000, 75.000 e 100.000 plantas por hectare. Médias seguidas pela mesma letra na coluna, para cada variável, não diferem significativamente pelo teste de Duncan ao nível de $5 \%$ (SANGOI et al., 2001a). 
óvulos recentemente fertilizados no início do enchimento de grãos (SANGOI, 2001). A disponibilidade adequada de açúcares solúveis e nitrogênio nas espigas e órgãos próximos no período compreendido entre a antese e o início da fase de dilatação dos grãos, é fundamental para que a intensa atividade mitótica verificada nos óvulos recém-fertilizados possa ser mantida (SALVADOR e Pearce, 1995). Assim, a utilização de altas densidades promove limitações no suprimento de carbono e nitrogênio às espigas logo após a fertilização, favorecendo o aborto de grãos no início de sua formação (LEMCoff e LOOMIS, 1986; SETTER et al., 2001). Isso ocorre com maior freqüência com os grãos localizados na ponta da espiga, os quais são os últimos a serem fertilizados, tendo, por conseguinte, menor poder de demanda dentro da espiga por carboidratos e compostos nitrogenados $(7)$.

A maior sincronia entre antese e espigamento e o maior número de grãos por espiga exteriorizados pelos híbridos modernos de milho em altas densidades também decorrem de sua maior eficiência em suprir carboidratos e compostos nitrogenados à espiga nas fases de pré-floração, floração e início do enchimento de grãos (SANGOI et al., 2001a). A arquitetura de planta que caracteriza os híbridos modernos de milho contribuiu para a manutenção de taxas fotossintéticas mais altas quando se incrementa a densidade de semeadura (Almeida et al., 2000b). Nesse sentido, a presença de plantas com menor número de folhas, folhas mais eretas e menor produção de fitomassa reduz o nível de interferência de uma planta sobre a outra. Com isso, pode-se utilizar maior número de indivíduos por área, aumentando a eficiência de interceptação da radiação solar (TollenAAR et al., 1997) e possibilitando taxas fotossintéticas mais altas (DWYER et al., 1991). Com maiores taxas fotossintéticas, há maior disponibilidade de fotoassimilados para que a comunidade de plantas possa produzir mais massa seca (SINCLAIR, 1998) e sustentar um desenvolvimento harmonioso das inflorescências masculina e feminina. Isso permite que a planta atenda adequadamente às demandas do pendão e das espigas, levando a um maior sincronismo entre antese e espigamento (SANGOI, 2001) e a maior número de grãos produzidos por espiga (ANDRADE et al., 1999; VEgA et al., 2001a,b). Dessa forma, a maior eficiência da fonte em suprir os diferentes drenos da planta em períodos críticos para a definição do número de grãos por espiga é causa importante para maior adaptação dos híbridos modernos de milho a elevadas densidades de plantas.

\subsection{Eficiência de uso do nitrogênio e relação entre fonte e dreno}

O nível de fertilidade do solo, em geral, não é utilizado diretamente como uma ferramenta de seleção no processo de desenvolvimento e avaliação de futuras linhagens de milho (Russel, 1991). Assim, os campos de produção de híbridos e linhagens são normalmente conduzidos em áreas bem fertilizadas, de forma que as exigências nutricionais da cultura sejam atendidas e não apresentem restrições ao progresso do programa de melhoramento (KAMPRATH et al., 1982). Contudo, a pressão de seleção utilizada para aumentar a tolerância da cultura ao adensamento resultou no desenvolvimento de genótipos que convertem o nitrogênio mais eficientemente à produção de grãos (SANGOI et al., 2001b).

Segundo Huber (1994), existem quatro características que determinam a resposta do rendimento de grãos de milho à disponibilidade de nitrogênio: as taxas de absorção do nutriente ao longo do ciclo da cultura, a capacidade de armazenamento de $\mathrm{N}$ nas estruturas vegetativas da planta, a eficiência de reciclagem do nitrogênio das frações vegetativas para as estruturas reprodutivas e o poder de demanda dos grãos por compostos nitrogenados e carbonados.

Trabalhos realizados por McCullough et al. $(1994 a, b)$, no Canadá, demonstraram que a maior eficiência de uso do nitrogênio de um híbrido moderno em comparação com um híbrido antigo esteve associada às maiores taxas de absorção do nitrogênio e à maior quantidade de $\mathrm{N}$ por unidade de área foliar. Tais características permitiram ao híbrido moderno concentrar maiores teores de clorofila nas folhas e manter taxas de assimilação de carbono mais altas, especialmente, sob baixa disponibilidade de nitrogênio no solo.

SANGOI et al. (2001b), comparando a resposta de híbridos de milho semeados em alta densidade de plantas (75.000 plantas por hectare) a doses de nitrogênio em cobertura, constataram que os híbridos antigos acumularam maior quantidade de nitrogênio na parte aérea das plantas na floração do que os híbridos contemporâneos, quando submetidos a doses de $\mathrm{N}$ superiores a $100 \mathrm{~kg}$.ha ${ }^{-1}$ (Figura 3). A alta disponibilidade de compostos nitrogenados, contudo, não preveniu a ocorrência de assincronia entre antese e espigamento nesses genótipos, fazendo com que produzissem menos grãos por espiga (Figura 4) e grãos mais leves do que os híbridos modernos, independentemente da dose de $\mathrm{N}$ utilizada no trabalho.

(7) ARGENTA, G.; SANGOI, L.; SILVA, P.R.F.; RAMPAZZO, C.; GRACIETTI, L.C.; STRIEDER, M.L.; FORSTHOFER, E.L.; SUHRE, E. Avaliação do potencial de rendimento de grãos do milho em dois ambientes contrastantes. Sciencia Agraria (submetido para publicação). 


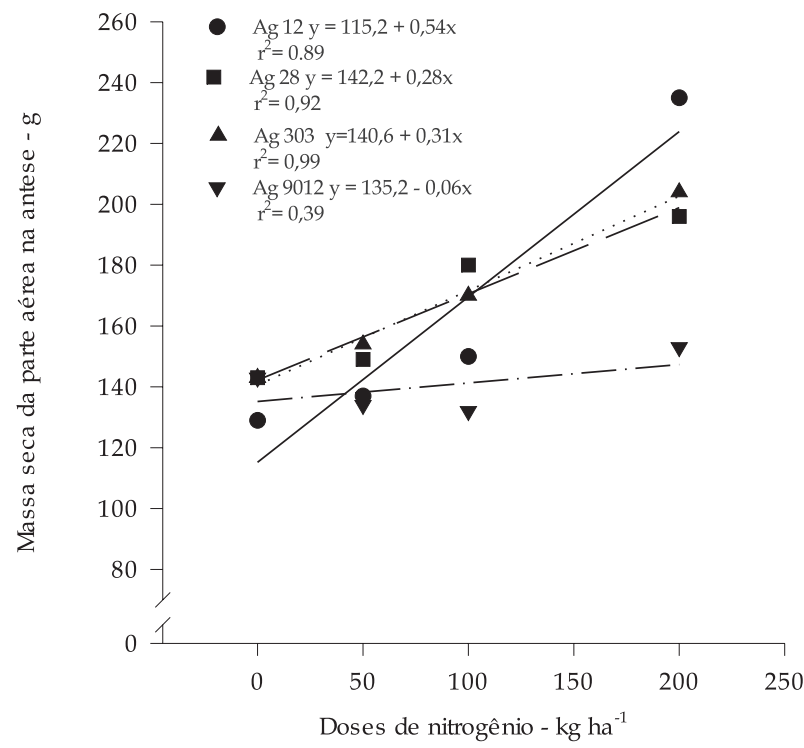

Figura 3. Efeito de doses de nitrogênio em cobertura sobre o acúmulo de massa seca na parte aérea durante a antese de híbridos de milho cultivados nas décadas de 60 (Agroceres 12), 70 (Agroceres 28), 80 (Agroceres 303) e 90 (Agroceres 9012), Lages, SC, 1998/99 (SANGOI et al., 2001b).

O aumento da assincronia floral, estimulado por condições de estresse, reduz o número de óvulos fertilizados, suprimindo o poder de demanda da espiga durante o enchimento de grãos (SANGOI e SALVADOR, 1998a). A redução do poder de demanda da espiga contribui para a diminuição da atividade fotossintética das folhas (RAJCAN e TOLLENAAR, 1999a). A menor atividade fotossintética das folhas reduz o suprimento de carboidratos às raízes, o qual é fundamental para a absorção do nitrogênio e de outros nutrientes na fase reprodutiva da cultura (RAjcan e TollenaAR, 1999b). Coletivamente, a seqüência de eventos acelera a senescência foliar, encurtando o período de enchimento de grãos e levando à produção de grãos mais leves. ToLLENAAR e Aguilera (1992) associaram o menor acúmulo de massa seca nos grãos de híbridos antigos de milho do Canadá à sua senescência foliar mais rápida. Por outro lado, Duvick (1992) e RAJCAN e TOLlenAAR (1999a) enfatizaram a importância do caráter "stay green" para o melhor desempenho demonstrado pelos híbridos modernos em altas densidades no cinturão do milho norte-americano. Como densidades elevadas promovem problemas mais acentuados de assincronia floral nos híbridos antigos (SANGOI et al., 2001b), deduz-se que a maior adaptação dos híbridos modernos ao aumento na densidade refere-se à relação entre fonte e demanda mais equilibrada, a qual é fundamental para manter o aparato fotossintético da planta fisiologicamente ativo por mais tempo. Isso preserva o crescimento

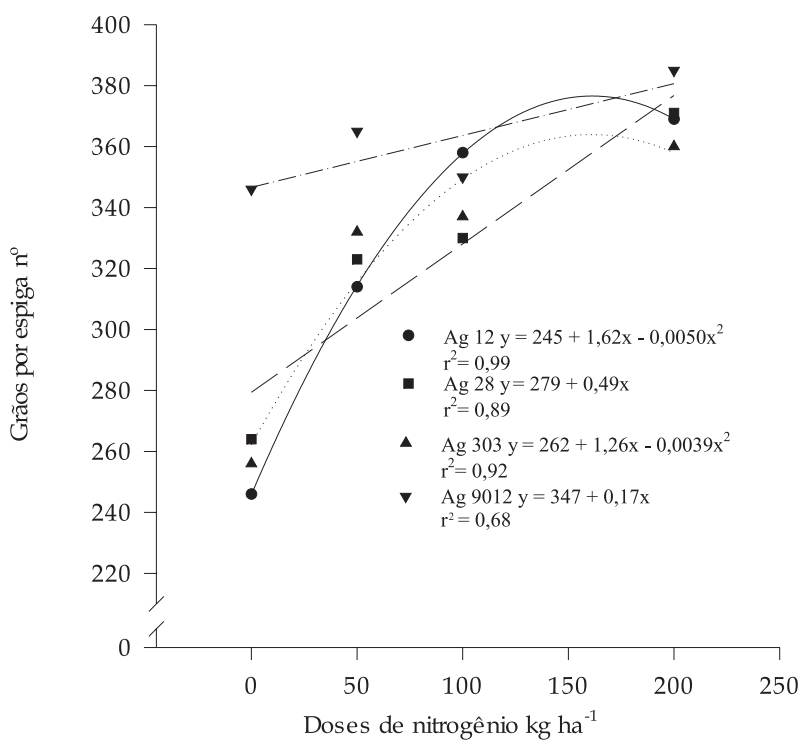

Figura 4. Efeito de doses de nitrogênio em cobertura sobre o número de grãos por espiga de híbridos de milho cultivados nas décadas de 60 (Agroceres 12), 70 (Agroceres 28), 80 (Agroceres 303) e 90 (Agroceres 9012), Lages, SC, 1998/99 (SANGOI et al., 2001b).

radicular, resultando em maior absorção de nutrientes no período de enchimento de grãos e, conseqüentemente, em maior produtividade por área ao final do ciclo da cultura (SANGOI et al., 2001a).

\subsection{Arquitetura de planta, acamamento e quebra de colmos}

A menor oxidação de auxinas decorrente da proximidade das plantas em densidades elevadas estimula a elongação celular (SALISBURRY e Ross, 1992). Com isso, os entrenós do colmo são mais longos, aumentando a estatura da planta e a altura de inserção de espigas. Além disso, a maior competição intra-específica por luz, o aumento da dominância apical e o estiolamento das plantas favorecem a redução no diâmetro do colmo.

$\mathrm{O}$ incremento da densidade de plantas aumenta a competição entre indivíduos por água, luz e nutrientes, reduzindo a disponibilidade de fotoassimilados para atender à demanda para enchimento dos grãos e manutenção das demais estruturas da planta (SANGOI e SALVADOR, 1997). Após a floração, o fluxo de fotoassimilados dentro da planta é direcionado prioritariamente ao enchimento de grãos. Quando o aparato fotossintético não produz fotoassimilados em quantidade suficiente para a manutenção dos tecidos, a maior demanda exercida pelos grãos por esses produtos leva os tecidos da raiz e da base do colmo a senescerem precocemente, fragilizando essas regiões (TOLLENAAR et al., 1994). 
A maior estatura de planta, a maior distância entre o ponto de inserção da espiga no colmo e o solo, o menor diâmetro do colmo e a sua maior fragilidade em altas densidades favorecem o aumento da porcentagem de plantas acamadas e quebradas antes da colheita. A redução na sustentabilidade da planta e a maior incidência de doenças são as duas limitações mais importantes ao aumento da densidade na lavoura de milho (ARGENTA et al., 2001).

A arquitetura de plantas dos híbridos modernos contribui para reduzir a sua suscetibilidade ao acamamento e quebra de colmos. SANGOI (2001a), comparando a sustentabilidade dos híbridos Agroceres 12 e Agroceres 303 (cultivados nas décadas de 60 e 80 respectivamente) com o híbrido Cargill 929 (cultivado atualmente) na densidade de 100.000 plantas por hectare, verificou que os híbridos antigos apresentaram mais de $20 \%$ das plantas acamadas e quebradas na colheita, enquanto o híbrido moderno manteve todas as plantas eretas até o final do ciclo da cultura (Figura 5). Tais características foram atribuídas à maior precocidade, à menor estatura de plantas, à menor área foliar e à presença de folhas mais curtas e eretas do híbrido moderno (Quadro 1).

A menor exigência em unidades de calor para florescimento dos híbridos contemporâneos doSul do Brasil, favorece a produção de plantas com menor altura de inserção de espigas. Com isso, o centro de gravidade da planta fica mais bem equilibrado, aumentando sua sustentabilidade (SANGOI et al., 2001a). A arquitetura de planta compacta facilita a penetração de radiação solar no interior da

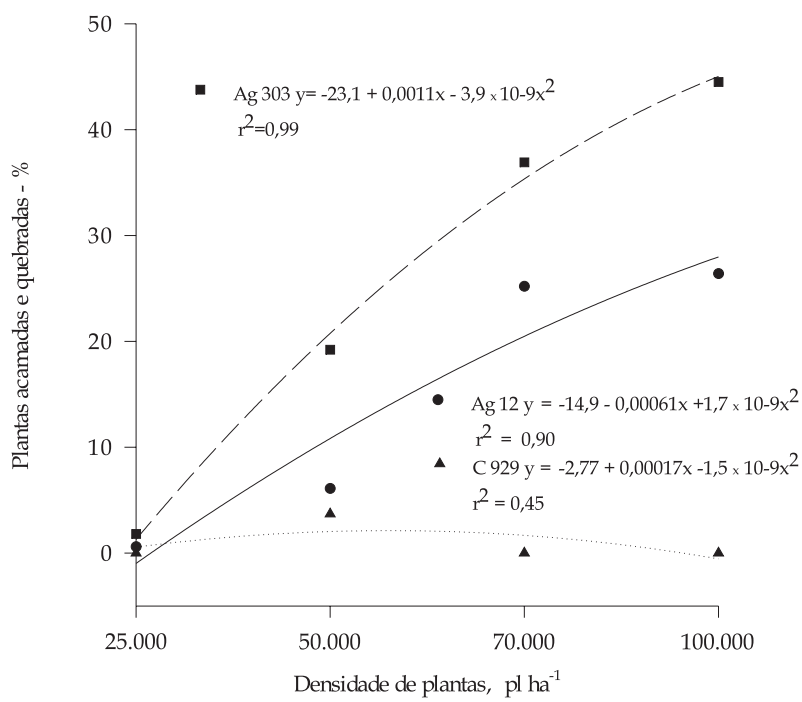

Figura 5. Efeitos da densidade de plantas sobre a percentagem de plantas acamadas e quebradas de híbridos de milho cultivados nas décadas de 60 (Agroceres 12), 80 (Agroceres 303) e 90 (Cargill 929), Lages, SC, 2000/2001 (SANGOI et al., 2001a). comunidade, até mesmo em lavouras instaladas com estandes adensados. Desse modo, há maior oxidação de auxinas e menor estímulo ao crescimento em estatura. O menor tamanho do pendão dos genótipos contemporâneos também é fator restritivo à produção desse fitormônio (SANGOI e SALVADOR, 1996), limitando o porte da planta. O menor número de folhas por planta e a presença de folhas curtas e eretas contribuem para aumentar a eficiência de interceptação da radiação solar e, conseqüentemente, a capacidade fotossintética da planta, em lavouras com índice de área foliar elevado. A maior capacidade do aparato fotossintético em fixar $\mathrm{CO}_{2}$ influencia o fracionamento dos produtos da fotossíntese durante o período de enchimento de grãos (SANGOI et al., 2001c; 2002). A maior eficiência fotossintética dos híbridos modernos lhes permite remobilizar menor quantidade de reservas dos colmos para os grãos, prevenindo a incidência de doenças e limitando o acamamento ao final do ciclo da cultura (SANGOI et al., 2000).

\section{CONCLUSÕES}

1. A maximização do potencial produtivo das plantas cultivadas depende da duração do período de interceptação da radiação solar incidente, da eficiência de uso da radiação interceptada na fotossíntese e da distribuição adequada dos fotoassimilados produzidos para atender às diferentes demandas. O incremento na densidade de plantas maximiza a interceptação da radiação solar da cultura do milho. Contudo, pode reduzir a eficiência de sua conversão à produção de grãos, favorecer a esterilidade feminina, aumentar o intervalo entre antese e espigamento e reduzir o número de grãos por espiga.

2. A alta sensibilidade dos híbridos antigos de milho ao uso de densidades elevadas motivou os programas de melhoramento a desenvolverem genótipos mais bem adaptados ao estresse ocasionado por altas densidades. Progressos consideráveis ocorreram nesse sentido, contribuindo para que muitos híbridos cultivados atualmente no Sul do Brasil apresentem menor porcentagem de plantas sem espiga, maior sincronia floral e tetos produtivos mais altos que os híbridos empregados no passado, quando cultivados em altas densidades. Tais avanços foram feitos sem preocupação acentuada em compreender as bases morfofisiológicas responsáveis pelos progressos obtidos.

3. A integração entre fisiologia, ecologia e melhoramento é vital para continuar aperfeiçoando um ideotipo de milho cada vez mais eficiente na utilização dos recursos do ambiente. A compreensão dos mecanismos que permitiram ao milho suportar o aumento da competição intra-específica e alcançar altos rendimentos de grãos é de grande utilidade para 
que melhoristas e fisiologistas continuem manipulando o arranjo de plantas na lavoura a fim de maximizar a interceptação da radiação solar, otimizar seu uso e potencializar o rendimento de grãos. Além disso, é importante que se trabalhe na melhoria do nível de fertilidade dos solos e da disponibilidade hídrica à cultura, para que se possa utilizar, efetivamente, a maior tolerância dos híbridos contemporâneos a altas densidades populacionais como uma ferramenta auxiliar ao incremento do rendimento de grãos da lavoura de milho brasileira.

\section{REFERÊNCIAS BIBLIOGRÁFICAS}

ALMEIDA, M.L. de. Modificação do afilhamento de trigo e aveia pela qualidade da luz. 1998. 120f. Dissertação (Doutorado) - Universidade Federal do Rio Grande do Sul, Porto Alegre.

ALMEIDA, M.L.; MUNDSTOCK, C.M.; SANGOI, L. Evocação de afilhos pela qualidade da luz em plantas de trigo cultivadas em diferentes substratos. Revista Brasileira de Fisiologia Vegetal, Viçosa, v.12 , n.1, p.2536, 2000a.

ALMEIDA, M.L.; SANGOI, L.; ENDER, M. Incremento na densidade de plantas: uma alternativa para aumentar o rendimento de grãos de milho em regiões de curta estação estival de crescimento. Ciência Rural, Santa Maria, v.30, n.1, p.23-29, 2000b.

ALMEIDA, M.L.; SANGOI, L.; TRENTIN, P.S.; GALIO, J. Cultivares de trigo respondem diferentemente à qualidade da luz quanto à emissão de afilhos e acumulação de massa seca Ciência Rural, Santa Maria , v.32, n.3, p.377-383, 2002.

ANDRADE, F.H.; CIRILO, A.; ECHARTE, L. Factors affecting kernel number in maize. In: OTEGUI, M.; SLAFFER, G.A. (Eds.). Physiological bases for maize improvement. New York: Haworth Press, 2000. cap.5, p.59-71.

ANDRADE, F.H.; VEGA, C.; UHART, S.; CIRILO, A.; CANTARERO, M.; VALENTINUZ, O. Kernel number determination in maize. Crop Science, Madison, v.39, n.2, p.453-459, 1999.

ARGENTA, G.; SILVA, P.R.F.; SANGOI, L. Arranjo de plantas em milho: análise do estado da arte. Ciência Rural, Santa Maria, v.31, n.5, p.1075-1084, 2001.

BOLAÑOS, J.; EDMEADES, G. The importance of the anthesis-silking interval in breeding for drought tolerance in tropical maize. Field Crops Research, Amsterdan, v.31, n.2, p.233-252, 1996.

CANTARERO, M.G.; CIRILO, A.G.; ANDRADE, F.H. Night temperature at silking affects kernel set in Maize. Crop Science, Madison, v.39, n.3, p.703-710, 1999.

CHENG, P.C.; PAREDY, D.R. Morphology and development of the tassel and ear. In: FREELING, M.; WALBOT, V. The Maize Handbook. NewYork: Springler-Verlag, 1994. cap.3, p.37-47.
DUVICK, D.N. Genetic contributions to advances in yield of U.S. maize. Maydica, Bergamo, v.37, n.1, p.69-79, 1992.

DUVICK, D.N.; CASSMAN, K.G. Post-green revolution trends in yield potential of temperate maize in the North-Central United States. Crop Science, Madison, v.39, n.6, p.1622-1630, 1999.

DWYER, L.M.; TOLLENAR, M.; STEWART, D.W. Changes in plant density dependence of leaf photosynthesis of maize (Zea mays L.) hybrids, 1959 to 1988. Canadian Journal Plant Science, Quebec, v.71, p.1-11, 1991.

GARDNER, F.P.; PEARCE, R.B.; MITCHELL, R.L. Physiology of crop plants. Ames: Iowa State University, 1985. 327p.

HUBER, D.M.; TSAI, C.Y.; STROMBERGER, J.A. Interaction of $\mathrm{K}$ with $\mathrm{N}$ and their influence on growth and yield potential of maize. In: ANNUAL CORN AND SORGHUM RESEARCH CONFERENCE, 48., 1994, Chicago. Proceedings... Washington: American Seed Company Association, 1994. p.165-176.

JACOBS, B.J.; PEARSON, C.J. Potential yield of maize. determined by rates of growth and development of ears. Field Crops Research, Amsterdam, v.27, n.2, p.281-298, 1991.

KAMPRATH, E.J.; MOLL, R.H.; RODRIGUEZ, N. Effects of nitrogen fertilization and recurrent selection on performance of hybrids populations of corn. Agronomy Journal, Madison, v.74, n.6, p.955-958, 1982.

KASPERBAUER, M.J.; KARLEN, D.L. Plant spacing and reflected far-red light effects on phytochromeregulated photosynthate allocation in corn seedlings. Crop Science, Madison, v.34, n.6, p.1564-1569, 1994.

KIRINY, J.R.; OTEGUI, M.E. Processes affecting maize grain yield potential in temperate conditions. In: OTEGUI, M., SLAFFER, G.A. (Eds.). Physiological bases for maize improvement. . New York: Haworth Press, 2000. cap.3, p.31-46.

LEMCOFF, J.H.; LOOMIS, R.S. Nitrogen and density influences on silk emergence, endosperm development, and grain yield of maize (Zea mays L.). Field Crops Research, Amsterdam, v.38, n.1, p.63-72, 1994.

LEMCOFF, J.H.; LOOMIS, R.S. Nitrogen influences on yield determination in maize. Crop Science, Madison, v.26, n.5, p.1017-1022, 1986

McCULLOUGH, D.E.; AGUILERA, A.; TOLLENAAR, M. N uptake, N partitioning, and photosynthetic N-use efficiency of an old and a new maize hybrid. Canadian Journal of Plant Science, Ottawa, v.74, n.2, p.479-484, 1994b.

McCULLOUGH, D.E.; GIRARDIN, P.; MIHAJLOVIC, M.; AGUILERA, A.; TOLLENAAR, M. Influence of N supply on the development and dry matter accumulation of an old and a new maize hybrid. Canadian Journal of Plant Science, Ottawa, v.74, n.2, p.471-478, 1994a. 
MUNDSTOCK, C.M. Bases fisiológicas para aumentar o rendimento de milho no sul do Brasil. In: REUNIÃO TÉCNICA CATARINENSE DE MILHO E FEIJÃO, 2., 1999. Lages. Resumos... Passo Fundo: Editora Padre Berthier, 1999. p.31-33.

OTEGUI, M.E.; NICOLINI, M.G.; RUIZ, R.A.; DODDS, P.A. Sowing date effects on grain yield components of different maize genotypes. Agronomy Journal, Madison, v.87, n.1, p.29-33, 1995.

PEIXOTO, C.M.; SILVA, P.R.F. da; REZER, F. et al. Produtividade de híbridos de milho em função da densidade de plantas, em dois níveis de manejo da água e da adubação. Pesquisa Agropecuária Gaúcha, Porto Alegre, v.3, n.1, p.63-71, 1997.

RAJCAN, I.; TOLLENAAR, M. Source:sink ratio and leaf senescence in maize: I. Dry matter accumulation and partitioning during grain filling. Field Crops Research, Amsterdan, v.60, n.2, p.245-253, 1999a.

RAJCAN, I.; TOLLENAAR, M. Source:sink ratio and leaf senescence in maize: II. Nitrogen metabolism during grain filling. Field Crops Research, Amsterdan, v.60, n.2, p.255-265, 1999b.

RITCHIE, S.W.; HANWAY, J.J. How a corn plant develops. Ames: Iowa State University of Science and Technology, 1993. 26p. (Special Report, 48).

RUSSEL, W.A. Genetic improvement of maize yields. Advances in Agronomy, Cambridge, v.46, n.1, p.245-298, 1991.

SALISBURRY, F.B.; ROSS, C.W. Plant Physiology. 4.ed. Belmont: Wadsworth Publishing, 1992. 681p.

SALVADOR, R.J.; PEARCE, R.B. Proposed standard system of nomenclature for maize grain filling events and concepts. Maydica, Bérgamo, v.40, n.1, p.141-146, 1995.

SANGOI, L. An ideotype of maize for conditions of high temperature and low moisture. 1996. 350f. (Ph.D. Dissertation) - Iowa State Universtiy, Ames.

SANGOI, L. Understanding plant density effects on maize growth and development: an important issue to maximize grain yield. Ciência Rural, Santa Maria, v.31, n.1, p.159-168, 2001.

SANGOI, L.; ALMEIDA, M.L.; ENDER, M.; GUIDOLIN, A.F.; KONFLANZ, V.A. Nitrogen fertilization impact on agronomic traits of maize hybrids released at different decades. Pesquisa Agropecuária Brasileira, Brasília, v.36, n.5, p.757-764, 2001b .

SANGOI, L.; ALMEIDA, M.L.; LECH, V.A.; GRACIETTI, L.C.; RAMPAZZO, C. Desempenho de híbridos de milho com ciclos contrastantes em função da desfolha e da população de plantas. Scientia Agricola, Piracicaba, v.58, n.2 , p.271-276 , 2001c.

SANGOI, L.; ALMEIDA, M.L.; RAMPAZZO, C.; GRACIETTI, L.C. Resposta de híbridos de milho cultivados em diferentes épocas ao aumento da densidade de plantas. In. REUNIÂO TÉCNICA CATARINENSE DE MILHO E FEIJÃO, 3., 2001, Chapecó Resumos... Florianópolis: Epagri , 2001a. p.48 -52.
SANGOI, L.; ENDER, M.; GUIDOLIN, A.F.; BOGO, A.; KOTHE, D.M. Incidência e severidade de doenças de quatro híbridos de milho cultivados em diferentes densidades de planta. Ciência Rural, Santa Maria, v.30, n.1, p.17-21, 2000.

SANGOI, L.; ENDER, M.;GUIDOLIN, A.F.;KONFLANZ, V.A. A dominância apical do pendão sobre as espigas é menor em híbridos modernos de milho. In: Reunião Técnica Catarinense deMilhoe Feijão, 1., Chapecó. Resumos... Passo Fundo: Editora Padre Berthier, 1998, p14-18.

SANGOI, L.; LECH, V.A.; RAMPAZZO, C.; GRACIETTI, L.C. Acúmulo de matéria seca em híbridos de milho sob diferentes relações entre fonte e dreno. Pesquisa Agropecuária Brasileira, Brasília, v.37, n.3, p.259-267, 2002.

SANGOI, L.; SALVADOR, R.J. Agronomic performace of male-sterile and fertile maize genotypes at two plant populations. Ciência Rural, Santa Maria, v.26, n.3, p.377-388, 1996.

SANGOI, L.; SALVADOR, R.J. Dry matter production and partitioning of maize hybrids and dwarf lines at four plant populations. Ciência Rural, Santa Maria, v.27, n.1, p.1-6, 1997.

SANGOI, L.; SALVADOR, R.J. Effect of maize detasseling on grain yield tolerance to high plant density and drought stress. Pesquisa Agropecuária Brasileira, Brasília, v.33, n.5, p.677-684, 1998b.

SANGOI, L.; SALVADOR, R.J. Influence of plant height and leaf number on maize production at high plant densities. Pesquisa Agropecuária Brasileira, Brasília, v.33, n.3, p.297-306, 1998c.

SANGOI, L.; SALVADOR, R.J. Maize susceptibility to drought at flowering: a new approach to overcome the problem. Ciência Rural, Santa Maria, v.28, n.4, p.699-706, 1998a.

SETTER, T.M.; FLANNINGAN, B.A.; MELKONIAN, J. Loss of kernel set due to water deficit and shade in maize: carbohydrate supplies, abscisic acid, and cytokinins. Crop Science, Madison, v.41, n.5, p.15301540, 2001.

SILVA, P.R.F. da. Densidade e arranjo de plantas em milho. In: CONGRESSO NACIONAL DE MILHO E SORGO, 19., 1992, Porto Alegre. Conferências... Porto Alegre: Secretaria da Agricultura - CIENTEC-ABMS, 1992. p.291-294.

SINCLAIR, T.R. Historical changes in harvest index and crop nitrogen accumulation. Crop Science, Madison, v.38, n.2, p.638-643, 1998 .

SLAFFER, G.A.; OTEGUI, M. Is there a niche for physiology in future genetic improvement of maize yields? In: SLAFFER, G.A.; OTEGUI (Eds.). Physiological bases for maize improvement. New York: Haworth Press, 2000. cap.1, p.1-14.

TOLLENAAR, M.; AGUILERA, A. Radiation use efficiency of an old and a new maize hybrid. Agronomy Journal, Madison, v.84, n.3, p.536-541, 1992. 
TOLLENAAR, M.; AGUILERA, A.; NISSANKA, S.P. Grain yield is reduced more by weed interference in an old than in a new maize hybrid. Agronomy Journal, Madison, v.89, n.2, p.239-246, 1997.

TOLLENAAR, M.; McCULLOUGH, D.E.; DWYER, L.M. Physiological basis of the genetic improvement of corn. In: SLAFER, G.A. Genetic improvement of field crops. New York: Marcel Dekker, 1994. cap.4, p.183-236.

VEGA, C.R.C.; ANDRADE, F.H.; SADRAS, V.O. Reproductive partitioning and seed set efficiency in soybean, sunflower and maize. Field Crops Research, Amsterdan, v.72, p.163-175, 2001a.

VEGA, C.R.C.; ANDRADE, F.H.; SADRAS, V.O.; UHART, S.A.; VALENTINUZ, O.R. Seed number as a function of growth: a comparative study in soybean, sunflower and maize. Crop Science, Madison, v.41, p.748-754, 2001b.

WESTGATE, M.E. Seed formation in maize during drought. In: BOOTE, K.J., BENNETT, J.M., SINCLAIR, T.R.,. PAULSEN G.M. Physiology and determination of crop yield. Madison: American Society of Agronomy, 1994. cap.15, p.361-364. 